\title{
Evaluating the Therapeutic Potential of Cenicriviroc in the Treatment of Nonalcoholic Steatohepatitis with Fibrosis: A Brief Report on Emerging Data
}

This article was published in the following Dove Press journal:

Hepatic Medicine: Evidence and Research

\author{
Maria Paula Diaz Soto (D) \\ Joseph K Lim² \\ 'Department of Medicine, Yale School of \\ Medicine, New Haven, CT, USA; ${ }^{2}$ Yale \\ Liver Center and Section of Digestive \\ Diseases, Yale School of Medicine, New \\ Haven, CT, USA
}

\begin{abstract}
Non-alcoholic steatohepatitis (NASH) is associated with significant morbidity and mortality due to liver cirrhosis, liver failure, and hepatocellular carcinoma, and represents a leading indication for liver transplantation in the United States (U.S.). A growing spectrum of novel therapies are currently in clinical development and target several mechanisms of action which address hepatic steatosis, steatohepatitis, and hepatic fibrosis. Cenicriviroc (Allergan, Dublin, Ireland) is a novel oral antagonist of CC-motif chemokine receptors 2 and 5 (CCR2/5) which have demonstrated expression on circulating monocytes and Kupffer cells. Preclinical models have confirmed that CCR2/5 antagonism may block fat accumulation and Kupffer cell activation and disrupt monocyte/macrophage recruitment and hepatic stellate cell activation responsible for fibrogenesis. Herein we review results from the phase $2 \mathrm{~b}$ CENTAUR trial and study designs for the phase 2b TANDEM and phase 3 AURORA trials and discuss the potential role of cenicriviroc in future pharmacotherapy for NASH fibrosis.
\end{abstract}

Keywords: cenicriviroc, fatty liver, non-alcoholic steatohepatitis, liver fibrosis, antifibrotic therapy, clinical trials

\section{Introduction}

Nonalcoholic steatohepatitis (NASH) is the inflammatory subtype of nonalcoholic fatty liver disease (NAFLD) and is characterized by steatosis, hepatocyte injury (ballooning) and inflammation, with or without fibrosis. ${ }^{1}$ The presence of fibrosis increases the risk of disease progression to cirrhosis, end-stage liver disease, hepatocellular carcinoma and need for liver transplantation. ${ }^{2,3}$ Notably, fibrosis severity is the only histologic feature of NASH independently associated with liver related and all-cause mortality. ${ }^{4-6}$ Paralleling the epidemic of metabolic conditions such as obesity, type 2 diabetes mellitus, and dyslipidemia, the prevalence of NAFLD/NASH has been increasing over the past decade. ${ }^{7}$ NASHassociated cirrhosis has become the leading indication for liver transplantation in women and is the second leading indication in men. ${ }^{8}$ The global prevalence of NAFLD is estimated at approximately $25 \%$ of the world population, of whom $20 \%$ are expected to develop NASH. ${ }^{7,9,10}$ There are currently no US Federal Drug Administration (FDA) approved therapies for the treatment of NASH, highlighting an important unmet medical need. The aim of this concise review is to explore the therapeutic potential of cenicriviroc by summarizing key results of major preclinical
Professor of Medicine, Yale Liver Center and Section of Digestive Diseases, Yale School of Medicine, 333 Cedar Street, LMP 1080, New Haven, CT 06520-8019, USA

Tel + I (203) 737-6063

Fax + I (203) 785-7273

Email joseph.lim@yale.edu 
and clinical studies and discussing the future direction for cenicriviroc as a potential treatment for NASH.

\section{Cenicriviroc}

NASH is a complex entity in which numerous signaling pathways are involved in disease pathophysiology. Two specific pathways, macrophage-mediated inflammation and hepatic stellate cell activation, have been identified as key pathways in disease progression (Figure 1). ${ }^{11}$ Accumulation of fat in the liver may be associated with inflammation and hepatic injury (ballooning), which in turn may activate hepatocytes, liver macrophages (Kupffer cells) and hepatic stellate cells (HSC) to release chemokines which interact with the CCR2 receptor on circulating monocytes to promote infiltration into the liver where they differentiate into pro-inflammatory macrophages. ${ }^{12,13}$ This population of cells is referred to as monocyte-derived macrophages (MoMF) which are distinct from the tissue-resident macrophages, Kupffer cells (KC). ${ }^{12,13}$ Both MoMF and KC release proinflammatory cytokines such as transforming growth factor $\beta$ (TGF- $\beta$ ) and plateletdelivered growth factor (PDGF) which activates HSC. ${ }^{14,15}$ Activated HSC differentiate into myofibroblast-like cells which produce collagen resulting in liver fibrosis. ${ }^{16}$ The CCR5 chemokine receptor is also expressed in a subpopulation of lymphocytes and HCS and contributes to profibrogenic activation and proliferation. ${ }^{17,18}$ Cenicriviroc (CVC), an oral dual CCR2/CCR5 antagonist is under investigation as a potential treatment for NASH due to its broad spectrum of anti-inflammatory and anti-fibrotic effects. ${ }^{19}$

\section{Pre-Clinical Models}

CVC showed promising results in various preclinical models. Its effect on decreasing the migration of monocytes was proven in a thioglycolate-induced peritonitis mouse model in which CVC reduced monocyte infiltration into the peritoneal cavity. ${ }^{20}$ Likewise, in a carbon tetrachloride (CC14) mouse model, CVC significantly decreased MoMF in acutely injured liver tissue ${ }^{21}$ but did not change hepatic lymphoid populations in vivo. ${ }^{21}$ Additionally, the antifibrotic properties of CVC were demonstrated in a streptozocin/high fat mouse model, with significant reduction of collagen deposition in the liver, percentage of fibrosis area and NAFLD activity score (NAS) ${ }^{20}$ In the choline-deficient/high fat mouse model of NASH, CVC resulted in significant decreases in histologic and molecular markers (hepatic hydroxyproline levels, COL1A1 mRNA expression) of hepatic fibrosis, although without significant changes in hepatic steatosis or inflammation. ${ }^{22}$ These findings were corroborated by findings from a thioacetamide (TAA) rat model in which CVC resulted

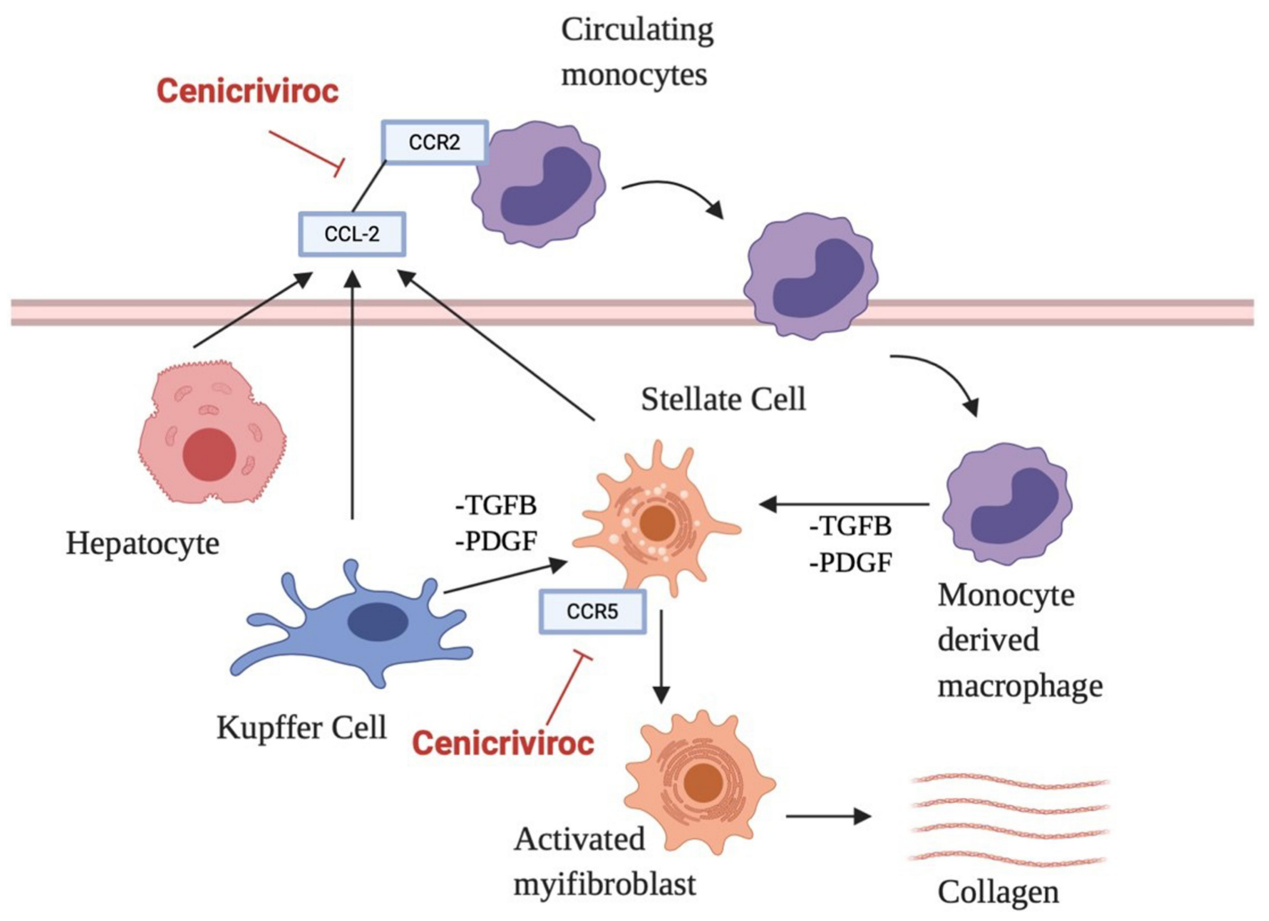

Figure I Cenicriviroc mechanism of action.

Abbreviations: CCL-2, chemokine (C-C motif) ligand 2; CCR2, C-C chemokine receptor 2; TFGB, transforming growth factor $\beta$; PDGF, platelet-derived growth factor. 
in a significant reduction of liver collagen deposition, ${ }^{20}$ and a decrease in insulin resistance, steatohepatitis and liver fibrosis in human liver tissue from patients with $\mathrm{NASH}^{23}$ Furthermore, pharmacologic inhibition of CCR2/5 signaling with CVC was associated with prevention and reversal of alcohol-induced liver injury, steatosis, and inflammation in a mouse model. ${ }^{24}$

\section{Safety and Tolerability}

A favorable safety and tolerability profile for CVC has been supported by several clinical studies including the Phase 1, open-label, nonrandomized, single-center study. ${ }^{25}$ In this study, 29 participants with mild (Child-Pugh class A) and moderate (Child-Pugh class B) hepatic insufficiency (HI) were matched by age, body weight and gender with healthy participants and were administered CVC $150 \mathrm{mg}$ daily for 14 days. CVC was well tolerated with few safety concerns identified in healthy participants and those with mild or moderate HI. Headache and gastrointestinal complaints were reported in two participants, and one patient experienced an increase in serum transaminases. No significant difference in adverse effects were observed between subjects on CVC versus matched controls, with matching of baseline levels of proinflammatory cytokines and bacterial translocation biomarkers. ${ }^{25}$

\section{Phase 2b Trial: CENTAUR}

The major Phase $2 b$ study evaluating CVC for the treatment of NASH was the CENTAUR trial (NCT02217475), ${ }^{26}$ which was a randomized, doubleblind, placebo-controlled, multinational study in which 289 adults with histological evidence of NASH, a NAS $\geq$ 4 including at least one point in each component, and liver fibrosis (NASH Clinical Research Network [CRN] stages 1-3) were enrolled across 81 trial sites in 10 countries. Subjects had either type 2 diabetes mellitus, overweight (body mass index $>25 \mathrm{~kg} / \mathrm{m}^{2}$ ), $\geq 1$ criteria of metabolic syndrome, bridging fibrosis (NASH CRN stage 3), or significant histologic disease activity (NAS $\geq 5$ ). Participants were randomized 2:1:1 to arm A (CVC $150 \mathrm{mg}$ daily for 2 years), arm B (placebo for 1 year then CVC $150 \mathrm{mg}$ daily for 1 year), or arm C (placebo for 2 years). ${ }^{24}$ The primary outcome was NASH improvement, defined as $\geq 2$-point improvement in NAS (with $\geq 1$-point reduction in either lobular inflammation or hepatocellular ballooning) and no worsening of fibrosis on liver biopsy upon completion of 1 year of treatment. Two important secondary outcomes included: 1) complete resolution of steatohepatitis (SH) without worsening of liver fibrosis; 2) improvement in liver fibrosis by $\geq 1$ stage (NASH CRN) without worsening of $\mathrm{SH}^{26}$ One-year follow-up results were available for 252 participants which confirmed that CVS failed to demonstrate a statistically significant improvement in the primary endpoint of NASH resolution, which was achieved in $1619 \%$ of patients treated with CVC and placebo, respectively $(\mathrm{p}=0.52)$. However, CVC was associated with a statistically significant improvement in the secondary endpoint of liver fibrosis of 1 stage or greater without worsening $\mathrm{SH}$, which was achieved in $2010 \%$ of patients treated with CVC and placebo, respectively $(\mathrm{p}=0.02)$. Importantly, subgroup analysis demonstrated greater effect of CVC on liver fibrosis among subjects with higher disease activity (NAS $\geq 5$, prominent hepatocellular ballooning) and liver fibrosis (stages 2 and 3), as well as more profound effects of CVC on reduction of systemic inflammatory markers including high sensitive $\mathrm{C}$ reactive protein (hsCRP), interleukin $1 \beta$ (IL-1 $\beta$ ), interleukin 6 (IL-6), and fibrinogen, although without effect on body weight or insulin resistance. ${ }^{26}$ These results strengthened the observation that CVC may have important direct antifibrotic effects in patients with $\mathrm{NASH}$ without affecting underlying steatohepatitis.

Two-year follow-up results in patients randomized to CVC versus placebo were subsequently reported and confirmed durability of liver fibrosis regression at the later timepoint, although without further reduction in liver fibrosis stage. ${ }^{27}$ Among patients who achieved at minimum a one stage fibrosis regression at one year, this endpoint was durable in $6030 \%$ of patients treated with CVC versus placebo, respectively, and subgroup analyses further revealed greater effects among patients with advanced liver fibrosis (stage 3). Overall comparison of the three trial arms confirmed a trend towards greater fibrosis regression of $\geq 1$ stage in the pooled group of patients treated with CVC in Arm A (CVC $150 \mathrm{mg}$ daily for 2 years) and Arm B (placebo for 1 year followed by CVC $150 \mathrm{mg}$ for 1 year) versus patients randomized to Arm C (placebo for 2 years) (19.9\% vs $11.1 \%, \mathrm{p}=0.09)$. Furthermore, patients treated with CVC in Arm B (placebo for 1 year followed by CVC $150 \mathrm{mg}$ for 1 year) demonstrated a trend towards greater fibrosis progression of $\geq 1$ stage versus Arm C (placebo for 2 years) (24.4\% vs $17.1 \%, \mathrm{p}=0.37)$. An additional trend was observed for a larger proportion of patients treated with CVC in Arm A and Arm B who achieved $\geq 2$ stage fibrosis regression 
than patients randomized to Arm $\mathrm{C}$ (placebo for 2 years) ( $15.8 \%$ vs $4.8 \%, \mathrm{p}=0.18)$.

The investigators additionally observed that $53 \%$ of patients who experienced worse liver fibrosis at the end of year 1 experienced fibrosis improvement at the end of year 2, which may represent natural fluctuation and/or variability in the natural history of NASH fibrosis, particularly in individuals with less severe liver disease. Furthermore, the significant proportion of subjects randomized to placebo who achieved histologic endpoints for NASH activity and liver fibrosis were consistent with other studies that revealed similar placebo results, reflecting the impact of standardized lifestyle interventions in all study subjects across trial arms. ${ }^{28,29}$ The authors further reported independent findings of the association between changes in a novel fibrosis biomarker PRO-C3 (procollagen $\mathrm{C} 3$ pro-peptide that reflects formation of type III collagen) and liver fibrosis regression, signaling potential utility as a noninvasive NASH biomarker. ${ }^{30}$

Overall, CENTAUR showed a favorable tolerability and safety profile for CVC. No significant differences were observed in treatment-emergent adverse events, adverse events leading to treatment discontinuation, or serious adverse events. No deaths were observed in this phase $2 b$ trial. The most common adverse effects of grade 2 severity or greater among patients randomized to CVC included headache $(1.4 \%)$, fatigue $(2.8 \%)$, and diarrhea $(2.1 \%){ }^{25,31}$ Similar safety and tolerability were observed upon completion of year two of the protocol.

\section{Phase 3 Clinical Trial: AURORA}

CVC is now under evaluation in the phase 3 clinical trial AURORA. ${ }^{32}$ The AURORA trial was designed on the basis of findings from the CENTAUR trial, showing that those participants who are more likely to benefit from CVC are those with advanced disease. This phase 3 clinical trial aims to evaluate and confirm the efficacy and safety of CVC for the treatment of adults with NASH. The study is organized and carried out in two parts over 5 years. Part 1 includes 1200 participants with histological evidence of NASH and stage F2 or F3 fibrosis who are randomized 2:1 to CVC $150 \mathrm{mg}$ daily or placebo with primary endpoint at end of Year 1 of liver fibrosis regression $\geq 1$ stage without worsening of SH. Part 2 includes 800 participants with histological evidence of NASH and stage F3 fibrosis with primary endpoint of clinical endpoints including time to adjudicated event (death, histopathologic progression to cirrhosis, liver transplantation, Model of End-Stage Liver Disease
[MELD] score $\geq 15$, ascites, hospitalization due to liver decompensation). The primary objective of part 2 is to compare CVC vs placebo on the composite endpoint of histopathologic progression to cirrhosis, liver-related outcomes and all-cause mortality. Key exclusion criteria include presence of cirrhosis or hepatic decompensation, other known causes of chronic liver disease, prior or planned liver transplantation, HIV, alcohol consumption $>21$ units/week, $>5$ upper limit of normal for liver function tests, total bilirubin $>1.3 \mathrm{mg} / \mathrm{dL}$, INR $>1.3$, MELD score $>12$ and HbAlc $>9 \%$. Liver biopsy assessments are performed at screening, 1 year and 5 years, and patient reported outcome (PRO) measures are collected longitudinally over 5 years, including the Chronic Liver Disease QuestionnaireNonalcoholic Fatty Liver Disease, Work Productivity and Activity Impairment in NASH and 36-Item Short Form Health Survey Version $2 .^{32}$ The anticipated primary completion date for AURORA is October 2021.

\section{Phase 2b Combination Study: TANDEM}

Although early clinical data support direct antifibrotic effects of CVC, effects on metabolic components of NAFLD and NASH have been limited. Combination approaches to incorporate novel investigational agents targeting both metabolic and fibrosis endpoints are under active exploration to augment efficacy in histologic and clinical endpoints. In this context, the phase $2 b$ TANDEM trial $^{33}$ is a randomized, placebo-controlled, multicenter trial evaluating the combination of CVC and tropifexor (TXR). TXR is a non-bile acid farnesoid X receptor (FXR) agonist which has demonstrated important effects on bile acid, glucose, and lipid metabolism. ${ }^{34,35}$ TXR alone has shown efficacy in preclinical models of NASH in which it has reduced bile acid and triglyceride synthesis, and has decreased hepatic steatosis, hepatic inflammation, and hepatocyte ballooning. ${ }^{36}$ Preclinical and phase 1 studies evaluating the combination of TXR plus CVC have revealed a significant reduction in hepatic inflammation and ballooning with acceptable safety and tolerability. The all-oral combination of TXR and CVC is anticipated to demonstrate antisteatotic, anti-inflammatory and antifibrotic effects. The primary objective of the phase $2 b$ TANDEM trial is to evaluate the safety and tolerability of a TXR plus CVC combination regimen compared with TXR and CVC monotherapy in 200 patients with NASH and liver fibrosis stage F2/F3 over 48 weeks. The secondary objective will 
Table I Pre-Clinical Studies and Clinical Trials Evaluating Cenicriviroc for NASH Treatment

\begin{tabular}{|c|c|c|c|c|}
\hline & $\begin{array}{l}\text { Study } \\
\text { Type }\end{array}$ & Objectives & Description & Results \\
\hline $\begin{array}{l}\text { Antifibrotic Effects of the Dual } \\
\text { CCR2/CCR5 Antagonist } \\
\text { Cenicriviroc in Animal Models of } \\
\text { Liver and Kidney Fibrosis }\end{array}$ & $\begin{array}{l}\text { Pre- } \\
\text { clinical }\end{array}$ & $\begin{array}{l}\text { Evaluate CVCs anti-inflammatory and } \\
\text { antifibrotic effects in a range of pre- } \\
\text { clinical models }\end{array}$ & $\begin{array}{l}\text { I)Monocyte/macrophages recruitment } \\
\text { evaluated in mouse model of } \\
\text { thioglycolate induced peritonitis 2) } \\
\text { CVCs antifibrotic effects were } \\
\text { evaluated in thioacetamide induced rat } \\
\text { model of liver fibrosis and mouse } \\
\text { models of diet induced NASH }\end{array}$ & $\begin{array}{l}\text {-CVC significantly reduced } \\
\text { monocyte/macrophage } \\
\text { recruitment in vivo. } \\
\text {-Also showed significant reduction } \\
\text { in collagen deposition. } \\
\text {-In NASH model, CVC } \\
\text { significantly reduced NAFLD } \\
\text { activity score } \\
\text {-CVC did not affect body or liver } \\
\text { weight }\end{array}$ \\
\hline $\begin{array}{l}\text { Differential impact of the dual } \\
\text { CCR2/CCR5 inhibitor } \\
\text { cenicriviroc on migration of } \\
\text { monocyte and lymphocyte } \\
\text { subsets in acute liver injury }\end{array}$ & $\begin{array}{l}\text { Pre- } \\
\text { clinical }\end{array}$ & $\begin{array}{l}\text { Evaluate the impact of CVC in the } \\
\text { composition of myeloid and lymphoid } \\
\text { immune cell populations in acute liver } \\
\text { injury }\end{array}$ & $\begin{array}{l}\text { Acute liver injury was induced in mice } \\
\text { by single injection of CCL4 } \\
\text { intraperitoneally, CVC was given by } \\
\text { oral gavage }\end{array}$ & $\begin{array}{l}\text {-Simultaneous administration of } \\
\text { CCL4 and CVC in mice } \\
\text { significantly decreased the number } \\
\text { of MoMF in acutely injured livers } \\
\text {-CVC had no impact on the } \\
\text { composition of hepatic lymphoid } \\
\text { cell population in vivo }\end{array}$ \\
\hline $\begin{array}{l}\text { Prolonged cenicriviroc therapy } \\
\text { reduces hepatic fibrosis despite } \\
\text { steatohepatitis in a diet-induced } \\
\text { mouse model of nonalcoholic } \\
\text { steatohepatitis. }\end{array}$ & $\begin{array}{l}\text { Pre- } \\
\text { clinical }\end{array}$ & $\begin{array}{l}\text { Asses the efficacy and durability of } \\
\text { short and prolonged CVC therapy in } \\
\text { a diet induced mouse model of NASH }\end{array}$ & $\begin{array}{l}\text { Mice received } 4 \text { or } 14 \text { weeks of } \\
\text { standard chow or the choline deficient, } \\
\text { L-amino acid-defined high fat diet } \\
\text { (CDAHFD). CVC was initiated } \\
\text { simultaneously with the CDAHFD }\end{array}$ & $\begin{array}{l}\text {-High dose CVC in CDAHFD } \\
\text { mice for } 4 \text { and } 14 \text { weeks inhibited } \\
\text { intrahepatic accumulation of bone } \\
\text { marrow derived macrophages } \\
\text {-Despite ongoing steatohepatitis, } \\
\text { there was significantly less fibrosis } \\
\text { in CDAHFD mice receiving high } \\
\text { dose CVC for } 14 \text { weeks }\end{array}$ \\
\hline $\begin{array}{l}\text { Pharmacokinetics, Safety, and } \\
\text { CCR2/CCR5 Antagonist Activity } \\
\text { of CVC in Participants With Mild } \\
\text { or Moderate Hepatic } \\
\text { Impairment. }\end{array}$ & $\begin{array}{l}\text { Phase } \\
\text { । }\end{array}$ & $\begin{array}{l}\text { I)Compare the PK of CVC in } \\
\text { participants with mild or moderate } \mathrm{HI} \\
\text { (Child-Pugh A and B) with healthy } \\
\text { participants. 2) Evaluate the safety and } \\
\text { tolerability of CVC and its effects on } \\
\text { CCR2/CCR5 ligands, proinflammatory } \\
\text { cytokines, and biomarkers of bacterial } \\
\text { translocation. }\end{array}$ & $\begin{array}{l}\text { Open label, nonrandomized, single } \\
\text { center study. participants with mild } \\
\text { (Child-Pugh class A) and moderate } \\
\text { (Child-Pugh class B) HI were matched } \\
\text { by age, body weight and gender with } \\
\text { healthy participants and were given } \\
\text { CVC } 150 \mathrm{mg} \text { daily for } 14 \text { days. }\end{array}$ & $\begin{array}{l}\text {-CVC was well tolerated and no } \\
\text { safety concerns were identified in } \\
\text { healthy participants as well as } \\
\text { those with mild and moderate } \mathrm{HI} \text {. } \\
\text {-Moderate } \mathrm{HI} \text { but not mild } \mathrm{HI} \\
\text { increase } \mathrm{CVC} \text { exposure } \\
\text {-Proinflammatory cytokines and } \\
\text { bacterial translocation biomarkers } \\
\text { were no different between } \mathrm{HI} \text { and } \\
\text { healthy participants. }\end{array}$ \\
\hline CENTAUR part I & $\begin{array}{l}\text { Phase } \\
2 b\end{array}$ & $\begin{array}{l}\text { Primary: } \geq 2 \text {-point improvement in } \\
\text { NAS and no worsening of fibrosis } \\
\text { at year I. Secondary: Resolution of SH } \\
\text { and no worsening of fibrosis; } \\
\text { improvement of fibrosis } \geq \text { I stage and } \\
\text { no worsening of } \mathrm{SH}\end{array}$ & $\begin{array}{l}\text { Randomized, double blinded, placebo } \\
\text { controlled, multinational study of } 289 \\
\text { adults with NASH, a NAS } \geq 4 \text { at least I } \\
\text { in each component, and liver fibrosis } \\
\text { stages I-3. Participants were } \\
\text { randomized 2:I:I to arm A (CVC } \\
\text { 150mg daily for } 2 \text { years), arm } \\
\text { B (placebo for I year then CVC I50mg } \\
\text { daily for I year), or arm C (placebo for } \\
2 \text { years). }\end{array}$ & $\begin{array}{l}\text {-No significant difference between } \\
\text { CVC and placebo achieving } \\
\text { primary outcome } \\
\text {-Significant difference in the CVC } \\
\text { group of improvement in fibrosis } \\
\text { by } \geq \text { I stage and no worsening of } \\
\text { SH compared to those on placebo } \\
\text { - Subgroup analysis showed } \\
\text { greater CVC treatment benefits in } \\
\text { subjects with higher disease } \\
\text { activity and fibrosis stage } \\
\text { - CVC did not improve the } \\
\text { histologic component of HS (NAS } \\
\text { score) nor did it affect body } \\
\text { weight, liver function tests or } \\
\text { insulin resistance }\end{array}$ \\
\hline
\end{tabular}

(Continued) 
Table I (Continued).

\begin{tabular}{|c|c|c|c|c|}
\hline & $\begin{array}{l}\text { Study } \\
\text { Type }\end{array}$ & Objectives & Description & Results \\
\hline CENTAUR part II & $\begin{array}{l}\text { Phase } \\
2 b\end{array}$ & Same as above & $\begin{array}{l}\text { Of } 289 \text { participants } 242 \text { entered } \\
\text { the second year }\end{array}$ & $\begin{array}{l}\text {-Over } 2 \text { years a similar proportion } \\
\text { on CVC or placebo achieved > I } \\
\text { stage fibrosis and no worsening of } \\
\text { NASH } \\
\text { - Double the proportion on CVC } \\
\text { who achieved fibrosis response at } \\
\text { end of year I maintained benefit } \\
\text { at year } 2 \text { ( } 60 \% \text { vs } 30 \%) \text {. } \\
\text {-The durability of antifibrotic } \\
\text { response of CVC treatment was } \\
\text { higher in those with stage } 3 \\
\text { fibrosis }\end{array}$ \\
\hline AURORA & $\begin{array}{l}\text { Phase } \\
3\end{array}$ & $\begin{array}{l}\text { Part I: to demonstrate histologic } \\
\text { improvement at the end of I year with } \\
\text { CVC vs placebo, specifically } \\
\text { improvement in liver fibrosis > I stage } \\
\text { and no worsening of SH } \\
\text { part II: to demonstrate superiority of } \\
\text { CVC vs placebo on the composite } \\
\text { endpoint of histopathologic } \\
\text { progression to cirrhosis, liver related } \\
\text { clinical outcomes and all-cause } \\
\text { mortality. }\end{array}$ & $\begin{array}{l}\text { Part I will include } 1200 \text { participants } \\
\text { with histological evidence of NASH } \\
\text { and stage F2 or F3 fibrosis randomized } \\
\text { 2:I to CVC } 150 \mathrm{mg} \text { daily or placebo. } \\
\text { Part II will include } 800 \text { newly } \\
\text { randomized participants with } \\
\text { histological evidence of NASH and } \\
\text { stage F3 fibrosis plus the I200 } \\
\text { participants from part I }\end{array}$ & $\begin{array}{l}\text {-Primary completion date for is } \\
\text { estimated to be in Oct 2021. }\end{array}$ \\
\hline TANDEM & $\begin{array}{l}\text { Phase } \\
2 b\end{array}$ & $\begin{array}{l}\text { Primary: Evaluate the safety and } \\
\text { tolerability of TXR and CVC } \\
\text { combination therapy compared with } \\
\text { monotherapies in } 200 \text { patients with } \\
\text { NASH and liver fibrosis stage F2/F3 } \\
\text { over } 48 \text { weeks. Secondary: determine } \\
\text { efficacy of the combination regimen on } \\
\text { histological improvement (at least } \\
\text { a I-point improvement in fibrosis } \\
\text { score or resolution of steatohepatitis) } \\
\text { vs monotherapies. }\end{array}$ & $\begin{array}{l}\text { randomized, placebo controlled, } \\
\text { multicenter clinical trial. } \\
\text { Randomization I:I:I:I ratio to receive } \\
\text { either TXR I40ug qd, CVC I50mg qd, } \\
\text { TXR I40ug + CVC I50mg qd or TXR } \\
\text { 90ug + CVC 150mg qd }\end{array}$ & $\begin{array}{l}\text { Estimated completion date is } \\
\text { September } 2020 \text {. }\end{array}$ \\
\hline
\end{tabular}

Abbreviations: CCR2/CCR5, CC-motif chemokine receptors 2 and 5; CVC, cenicriviroc; NASH, non-alcoholic steatohepatitis; NAFLD, non-alcoholic fatty liver disease; CCL4, carbon tetrachloride; MoMF, monocyte-derived macrophages; CDAHFD, L-amino acid-defined high fat diet; PK, pharmacokinetics; HI, hepatic insufficiency; NAS, NAFLD activity score; HS, hepatic steatosis; TXR, tropifexor; qd, daily.

determine the efficacy of TXR plus CVC on histological improvement (at least a 1-point improvement in fibrosis score or NASH resolution) vs CVC or TXR monotherapy. Patients will be randomized in a 1:1:1:1 ratio to receive TXR 140ug qd, CVC 150mg qd, TXR 140ug + CVC 150mg qd or TXR 90ug + CVC 150mg qd. Additional study measures include liver fat content using MRI-PDFF, noninvasive fibrosis markers (enhanced liver fibrosis test, AST platelet ratio index, fibrosis-4 and NAFLD score, transient elastography), lipid parameters, markers for target engagement (fibroblast growth factor 19 and cholesten- 3-one C4) and markers of systemic inflammation and apoptosis. Based on the results of the phase 2b CENTAUR trial, the response rate of improvement in fibrosis of $\geq 1$ stage with CVC monotherapy at week 48 in patients with F2 and F3 fibrosis is modeled at approximately $35 \% .{ }^{27}$ TXR monotherapy is currently under investigation in an independent phase $2 \mathrm{~b}$ monotherapy study (FLIGHT-FXR); preliminary data have revealed robust, dose-dependent reductions in hepatic fat and liver transaminases versus placebo at 12 weeks. ${ }^{33}$ The TANDEM study is estimated to reach completion in September 2020. 
Table 2 Other Therapies in Phase 3 Clinical Trials for NASH (Clinicaltrials.gov)

\begin{tabular}{|l|l|l|l|l|l|}
\hline Trial & Phase & Drug & Mechanism & Primary Outcome & $\begin{array}{l}\text { Expected } \\
\text { Completion }\end{array}$ \\
\hline REGENERATE & $\begin{array}{l}\text { Phase } \\
3\end{array}$ & $\begin{array}{l}\text { Obeticholic } \\
\text { acid }\end{array}$ & FXR agonist & $\begin{array}{l}\text {-Improvement in fibrosis by } \geq \text { I stage with no worsening } \\
\text { NASH } \\
\text {-NASH resolution with no worsening of fibrosis } \\
\text {-All cause mortality and liver related events }\end{array}$ & Oct 2022 \\
\hline RESOLVE IT & $\begin{array}{l}\text { Phase } \\
3\end{array}$ & Elafibranor & PPAR $\alpha / \delta$ agonist & $\begin{array}{l}\text {-NASH resolution without worsening of fibrosis } \\
\text {-All cause mortality, cirrhosis, liver related clinical } \\
\text { outcomes }\end{array}$ & Dec 202I \\
\hline MONARCh & $\begin{array}{l}\text { Phase } \\
3\end{array}$ & $\begin{array}{l}\text { MSDC } \\
0602 \mathrm{~K}\end{array}$ & $\begin{array}{l}\text { Mitochondrial pyruvate } \\
\text { carrier inhibitor }\end{array}$ & $\begin{array}{l}\text {-Change in HbAIc } \\
\text {-Histological resolution of NASH }\end{array}$ & Dec 202I \\
\hline MAESTRO- & $\begin{array}{l}\text { Phase } \\
\text { NASH }\end{array}$ & Resmetirom & $\begin{array}{l}\text { Thyroid hormone } \\
\text { receptor } \beta \text { agonist }\end{array}$ & $\begin{array}{l}\text {-NASH resolution on histology } \\
\text {-All cause mortality, cirrhosis, liver related clinical } \\
\text { outcomes }\end{array}$ & March 2024 \\
\hline ARMOR & $\begin{array}{l}\text { Phase } \\
3\end{array}$ & Aramchol & $\begin{array}{l}\text { SCD-I modulator } \\
\text { Resolution of NASH or improvement in fibrosis by I } \\
\text { stage and no worsening of NASH }\end{array}$ & Dec 2024 \\
\hline
\end{tabular}

Abbreviations: FXR, farnesoid X receptor; NASH, non-alcoholic steatohepatitis; PPAR, peroxisome proliferator-activated receptor; SCD, stearoyl-CoA desaturase I.

\section{Future Directions}

NASH is associated with substantial morbidity and mortality, and in the absence of an FDA-approved treatment, novel pharmacologic agents are urgently needed. CVC is a novel oral antagonist of CC-motif chemokine receptors 2 and 5 (CCR2/5) which has demonstrated promising preclinical, early clinical, and phase $2 \mathrm{~b}$ data that support safety and efficacy in reversing liver fibrosis in patients with biopsy-confirmed NASH (Table 1). The phase 3 AURORA trial will provide further confirmation of the safety and efficacy profile to clarify the potential role for CVC in the treatment of NASH fibrosis. Additional studies evaluating its role in combination with alternative mechanisms of action focused on metabolic endpoints targeted at liver steatosis and steatohepatitis may help determine a future role as part of oral combination regimens. In addition to the phase 3 AURORA trial and phase $2 b$ TANDEM trial, multiple other novel pharmacologic agents are currently under investigation in phase 2 and 3 trials (Table 2). ${ }^{37-40}$ The regulatory framework for the approval of novel NASHspecific therapies requires demonstration of either histologic NASH resolution (without worsening liver fibrosis) or histologic liver fibrosis regression of at least one stage (without worsening NASH) within an adaptive phase 3/4 trial design with demonstration of clinical outcome improvement upon long-term follow-up. Although current trial design and endpoints are limited by heterogeneous clinical phenotypes, long latency period between diagnosis and clinical outcomes (eg, cirrhosis, liver cancer), intrinsic flaws and variability in the biopsy gold standard, and slow acceptance of validated NASH biomarkers, the continued expansion of novel investigational agents targeting a diverse spectrum of metabolic and fibrosis pathways have created optimism for major advances in the treatment of patients with NASH fibrosis.

\section{Abbreviations}

NASH, non-alcoholic steatohepatitis; US, United States; CCR, CC-motif chemokine receptor; NAFLD, non-alcoholic fatty liver disease; FDA, Federal Drug Administration; HSC, hepatic stellate cells.

\section{Funding}

There is no funding to report.

\section{Disclosure}

JKL reports research contracts (to Yale University) from Allergan, Conatus, Genfit, Gilead, and Intercept. The authors report no other conflicts of interest in this work.

\section{References}

1. Chalasani N, Younossi Z, Lavine JE, et al. The diagnosis and management of nonalcoholic fatty liver disease: practice guidance from the American Association for the Study of Liver Diseases. Hepatology. 2018;67(1):328-357. doi:10.1002/hep.29367

2. Nasr P, Ignatova S, Kechagias S, Ekstedt M. Natural history of nonalcoholic fatty liver disease: A prospective follow-up study with serial biopsies. Hepatol Commun. 2018;2(2):199-210. doi:10.1002/hep4.11 34 
3. Matteoni CA, Younossi ZM, Gramlich T, Boparai N, Liu YC, McCullough AJ. Nonalcoholic fatty liver disease: a spectrum of clinical and pathological severity. Gastroenterology. 1999;116 (6):1413-1419. doi:10.1016/S0016-5085(99)70506-8

4. Angulo P, Kleiner DE, Dam-Larsen S, et al. Liver fibrosis, but no other histologic features, is associated with long-term outcomes of patients with nonalcoholic fatty liver disease. Gastroenterology. 2015;149(2):389-97 e10. doi:10.1053/j.gastro.2015.04.043

5. Ekstedt M, Hagstrom H, Nasr P, et al. Fibrosis stage is the strongest predictor for disease-specific mortality in NAFLD after up to 33 years of follow-up. Hepatology. 2015;61(5):1547-1554. doi:10.1002/hep.27368

6. Younossi ZM, Stepanova M, Rafiq N, et al. Pathologic criteria for nonalcoholic steatohepatitis: interprotocol agreement and ability to predict liver-related mortality. Hepatology. 2011;53(6):1874-1882. doi: $10.1002 /$ hep. 24268

7. Younossi ZM, Koenig AB, Abdelatif D, Fazel Y, Henry L, Wymer M. Global epidemiology of nonalcoholic fatty liver disease-Metaanalytic assessment of prevalence, incidence, and outcomes. Hepatology. 2016;64(1):73-84. doi:10.1002/hep.28431

8. Noureddin M, Vipani A, Bresee C, et al. NASH leading cause of liver transplant in women: updated analysis of indications for liver transplant and ethnic and gender variances. Am J Gastroenterol. 2018;113 (11):1649-1659. doi:10.1038/s41395-018-0088-6

9. Estes C, Razavi H, Loomba R, Younossi Z, Sanyal AJ. Modeling the epidemic of nonalcoholic fatty liver disease demonstrates an exponential increase in burden of disease. Hepatology. 2018;67 (1):123-133. doi:10.1002/hep.29466

10. Younossi ZM, Tampi R, Priyadarshini M, Nader F, Younossi IM, Racila A. Burden of illness and economic model for patients with nonalcoholic steatohepatitis in the United States. Hepatology. 2019;69(2):564-572. doi:10.1002/hep.30254

11. Lefere S, Devisscher L, Tacke F. Targeting CCR2/5 in the treatment of nonalcoholic steatohepatitis (NASH) and fibrosis: opportunities and challenges. Expert Opin Investig Drugs. 2020;29(2):89-92. doi:10.1080/13543784.2020.1718106

12. Lefere S, Tacke F. Macrophages in obesity and non-alcoholic fatty liver disease: crosstalk with metabolism. JHEP Rep. 2019;1 (1):30-43. doi:10.1016/j.jhepr.2019.02.004

13. Devisscher L, Verhelst X, Colle I, Van Vlierberghe H, Geerts A. The role of macrophages in obesity-driven chronic liver disease. J Leukoc Biol. 2016;99(5):693-698. doi:10.1189/jlb.5RU0116-016R

14. Ju C, Tacke F. Hepatic macrophages in homeostasis and liver diseases: from pathogenesis to novel therapeutic strategies. Cell Mol Immunol. 2016;13(3):316-327. doi:10.1038/cmi.2015.104

15. Raeman R, Anania FA. Therapy for steatohepatitis: do macrophages hold the clue? Hepatology. 2018;67(4):1204-1206. doi:10.1002/hep.29630

16. Tsuchida T, Friedman SL. Mechanisms of hepatic stellate cell activation. Nat Rev Gastroenterol Hepatol. 2017;14(7):397-411. doi:10.1038/nrgastro.2017.38

17. Schwabe RF, Bataller R, Brenner DA. Human hepatic stellate cells express CCR5 and RANTES to induce proliferation and migration. Am J Physiol Gastrointest Liver Physiol. 2003;285(5):G94958. doi:10.1152/ajpgi.00215.2003

18. Marra F, Tacke F. Roles for chemokines in liver disease. Gastroenterology. 2014;147(3):577-94 e1. doi:10.1053/j. gastro.2014.06.043

19. Tacke F. Targeting hepatic macrophages to treat liver diseases. J Hepatol. 2017;66(6):1300-1312. doi:10.1016/j.jhep.2017.02.026

20. Lefebvre E, Moyle G, Reshef R, et al. Antifibrotic effects of the dual CCR2/CCR5 antagonist cenicriviroc in animal models of liver and kidney fibrosis. PLoS One. 2016;11(6):e0158156. doi:10.1371/journal.pone. 0158156

21. Puengel T, Krenkel O, Kohlhepp M, et al. Differential impact of the dual CCR2/CCR5 inhibitor cenicriviroc on migration of monocyte and lymphocyte subsets in acute liver injury. PLoS One. 2017;12(9): e0184694. doi:10.1371/journal.pone.0184694
22. Kruger AJ, Fuchs BC, Masia R, et al. Prolonged cenicriviroc therapy reduces hepatic fibrosis despite steatohepatitis in a diet-induced mouse model of nonalcoholic steatohepatitis. Hepatol Commun. 2018;2(5):529-545. doi:10.1002/hep4.1160

23. Ambade A, Lowe P, Kodys K, et al. Pharmacologic inhibition of CCR2/5 signaling prevents and reverses alcohol-induced liver damage, steatosis, and inflammation in mice. Hepatology. 2019;69 (3):1105-1121. doi:10.1002/hep.30249

24. Krenkel O, Puengel T, Govaere O, et al. Therapeutic inhibition of inflammatory monocyte recruitment reduces steatohepatitis and liver fibrosis. Hepatology. 2018;67(4):1270-1283. doi:10.1002/hep.29544

25. Lefebvre E, Gottwald M, Lasseter K, et al. Pharmacokinetics, safety, and CCR2/CCR5 antagonist activity of cenicriviroc in participants with mild or moderate hepatic impairment. Clin Transl Sci. 2016;9 (3):139-148. doi:10.1111/cts.12397

26. Friedman SL, Ratziu V, Harrison SA, et al. A randomized, placebo-controlled trial of cenicriviroc for treatment of nonalcoholic steatohepatitis with fibrosis. Hepatology. 2018;67(5):1754-1767. doi: 10.1002/hep. 29477

27. Ratziu V, Sanyal A, Harrison SA, et al. Cenicriviroc Treatment for Adults with Nonalcoholic Steatohepatitis and Fibrosis: final Analysis of the Phase 2b CENTAUR Study. Hepatology. 2020. doi:10.1002/ hep. 31108

28. Neuschwander-Tetri BA, Loomba R, Sanyal AJ, et al. Farnesoid $\mathrm{X}$ nuclear receptor ligand obeticholic acid for non-cirrhotic, non-alcoholic steatohepatitis (FLINT): a multicentre, randomised, placebo-controlled trial. Lancet. 2015;385(9972):956-965. doi:10.1016/S0140-6736(14)61933-4

29. Ratziu V, Harrison SA, Francque S, et al. Elafibranor, an agonist of the peroxisome proliferator-activated receptor-alpha and -delta, induces resolution of nonalcoholic steatohepatitis without fibrosis worsening. Gastroenterology. 2016;150(5):1147-59 e5. doi:10.1053/ j.gastro.2016.01.038

30. Daniels SJ, Leeming DJ, Eslam M, et al. ADAPT: an algorithm incorporating PRO-C3 accurately identifies patients with NAFLD and advanced fibrosis. Hepatology. 2019;69(3):1075-1086. doi:10.1002/hep.30163

31. Thompson M, Saag M, DeJesus E, et al. A 48-week randomized phase $2 b$ study evaluating cenicriviroc versus efavirenz in treatment-naive HIV-infected adults with $\mathrm{C}-\mathrm{C}$ chemokine receptor type 5-tropic virus. AIDS. 2016;30(6):869-878. doi:10.1097/ QAD.0000000000000988

32. Anstee QM, Neuschwander-Tetri BA, Wong VW, et al. Cenicriviroc for the treatment of liver fibrosis in adults with nonalcoholic steatohepatitis: AURORA Phase 3 study design. Contemp Clin Trials. 2019;89:105922. doi:10.1016/j.cct.2019.105922

33. Pedrosa M, Seyedkazemi S, Francque S, et al. A randomized, double-blind, multicenter, phase $2 \mathrm{~b}$ study to evaluate the safety and efficacy of a combination of tropifexor and cenicriviroc in patients with nonalcoholic steatohepatitis and liver fibrosis: study design of the TANDEM trial. Contemp Clin Trials. 2020;88:105889. doi:10.1016/j.cct.2019.105889

34. Ali AH, Carey EJ, Lindor KD. Recent advances in the development of farnesoid X receptor agonists. Ann Transl Med. 2015;3 (1):5.

35. Calkin AC, Tontonoz P. Transcriptional integration of metabolism by the nuclear sterol-activated receptors LXR and FXR. Nat Rev Mol Cell Biol. 2012;13(4):213-224. doi:10.1038/nrm3312

36. Tully DC, Rucker PV, Chianelli D, et al. Discovery of TRopifexor (LJN452), a highly potent non-bile acid FXR agonist for the treatment of cholestatic liver diseases and nonalcoholic steatohepatitis (NASH). J Med Chem. 2017;60(24):9960-9973. doi:10.1021/acs. jmedchem.7b00907

37. Sumida Y, Okanoue T, Nakajima A. Japan Study Group of N. Phase 3 drug pipelines in the treatment of non-alcoholic steatohepatitis. Hepatol Res. 2019;49(11):1256-1262. doi:10.1111/hepr.13425 
38. Reimer KC, Wree A, Roderburg C, Tacke F. New drugs for NAFLD lessons from basic models to the clinic. Hepatol Int. 2020;14 (1):8-23. doi:10.1007/s12072-019-10001-4

39. Cardoso AC, de Figueiredo-mendes C, C AV-N, Sanyal AJ. New drugs for non-alcoholic steatohepatitis. Liver Int. 2020;40(Suppl 1):96-101. doi:10.1111/liv.14354
40. Alkhouri N, Scott A. An update on the pharmacological treatment of nonalcoholic fatty liver disease: beyond lifestyle modifications. Clin Liver Dis. 2018;11(4):82-86. doi:10.1002/cld.708

\section{Publish your work in this journal}

Hepatic Medicine: Evidence and Research is an international, peerreviewed, open access journal covering all aspects of adult and pediatric hepatology in the clinic and laboratory including the following topics: Pathology, pathophysiology of hepatic disease; Investigation and treatment of hepatic disease; Pharmacology of drugs used for the treatment of hepatic disease. Issues of patient safety and quality of care will also be considered. The manuscript management system is completely online and includes a very quick and fair peer-review system, which is all easy to use. Visit http://www.dovepress.com/ testimonials.php to read real quotes from published authors.

Submit your manuscript here: https://www.dovepress.com/hepatic-medicine-evidence-and-research-journal 